\title{
A study to Assess the Knowledge Regarding Gestational Diabetes Mellitus among Pregnant Mothers and Self Care Practice of Gestational Diabetes Mellitus Management among Mothers with Diabetes in Pregnancy Attending Selected Hospitals of Kottayam District
}

\author{
Gesa George $^{1}$, T. Sasikala ${ }^{2}$, Remya Chidambaran ${ }^{3}$ \\ ${ }^{1}$ PhD Scholar, Rani Meyyammai College of Nursing, Annamalai University, Chidambarm-608002, Tamil Nadu, \\ India, ${ }^{2}$ Lecturer,RaniMeyyammai College of Nursing, Annamalai University, Chidambaram-608002, Tamil Nadu. \\ India, ${ }^{3}$ Vice-Principal, Sreesucheendra College of Nursing, Ernakulam, Kerala
}

\begin{abstract}
The study was conducted to assess thethe knowledge regardingGestational Diabetes Mellitus among pregnant mothers and self care practice of Gestational Diabetes Mellitus management among mothers with diabetes in pregnancy attending selected hospitals of Kottayam District. The objectives were to assess the level of knowledge regarding Gestational Diabetes Mellitus among pregnant mothers, to assess the self care practice of Gestational Diabetes Mellitus management among mothers with diabetes in pregnancy, to find association between level of knowledge regarding Gestational Diabetes Mellitus and selected demographic variables,to find correlation between knowledge and self care practice of Gestational Diabetes Mellitus management among mothers with diabetes in pregnancy. The research design used in the present study is non experimental descriptive design. The study was conducted among 60 antenatal mothers and 15 mothers with gestational diabetes mellitus by using non probability convenient sampling technique.In the present study it was found that $33.3 \%$ mothers had poor knowledge, $33.3 \%$ had average knowledge and $33.3 \%$ had good knowledge regarding Gestational diabetes mellitus. When comes to practice t $46.7 \%$ had satisfactory practices and $53.3 \%$ had good practice. There is a positive correlation between knowledge and practice $(p=0.04)$.
\end{abstract}

Keywords: Gestational diabetes mellitus, Knowledge, Practice.

\section{Introduction}

Pregnancy is one of the wonderful and noble services imposed by nature which no women can shrink. It is a period of happiness, excitement, expectancy, anxiety and fear. ${ }^{1}$ Some common maternal health condition or problems a women may experience during pregnancy are Anemia, UTI, Mental health condition, Hypertension, Gestational Diabetes mellitus, Obesity and Weight gain, Infection, Hyper emesis gravidarum. ${ }^{2}$

Diabetes Mellitus is a metabolic disorder that affects carbohydrate, fat and protein metabolism. ${ }^{3}$ Today the majority of the women have Type 2 diabetes or diabetes during pregnancy.International Diabetes Federation says that the prevalence of high blood glucose in pregnancy increase rapidly with age and is highest in women of 45 in $2017 .^{3}$

The main cause and risk factor of Gestational Diabetes Mellitus are age $>25$ years, pre-gestational obesity or excessive weight gain during pregnancy, family history of diabetes, personal history of poor obstetric outcome such as polyhydramnios, macrosomia, pre-eclampsia, fetal malformation of an ethnic group with a high risk prevalence of diabetes and history ofDiabetes Mellitus in previous pregnancy. ${ }^{4}$

Diabetes during pregnancy has been associated with increased perinatal mortality,an increased rate of caesarean sections, significant risk of macrosomia, and other neonatal morbidities, including serious birth 
trauma, hypoglycemia, hypocalcemia, polycythemia and hyperbilirubinemia.Management is therefore directed toward reducing perinatal mortality and morbidity, a goal that may be achieved by maintaining close surveillance of the mother and fetus and stringent glucose control. ${ }^{5}$

Need for Study: Diabetes is a metabolic disorder characterized by resistance to the action of insulin, insufficient insulin secretion or both. Diabetic Mellitus is the most common metabolic disorder that complicates $3-5 \%$ of all pregnancies and is a major cause of perinatal morbidity and mortality as well as maternal morbidity. ${ }^{6}$

As the incidence of both obesity and Diabetes Mellitus among woman of child bearing age continue to raise well, so as the prevalence of hyperglycemia in pregnancy. Gestational Diabetes Mellitus develops in 1 in 25 pregnancies worldwide. According to American Diabetic AssociationGestational Diabetes Mellitus is common condition affecting $7 \%$ of all pregnancies. Depending on the population sample and diagnostic criteria, prevalence range from $1-14 \%{ }^{7}$

It is the most common metabolic disorder in pregnant women, associated with serious maternal and neonatal complications. This phenomenon is initially diagnosed during late pregnancy. It is predicted that the number of diabetic patients is projected to double by 2030 , which will also affect pregnant women ${ }^{8}$

A prospective study on the prevalence of carbohydrate intolerance of varying degree in pregnant woman in western India (Maharashtra) .On 2005 -2007 the sample size were 1225 woman with average age of 25 to 40 years. The result shows that the prevalence of Gestational Diabetes Mellitus was 21.6\% and concluded that Gestational Diabetes Mellitus affect one fifth of pregnant female from western India. ${ }^{9}$

From the above studies, it clearly shows that Gestational Diabetes Mellitus drastically increasing year by year now it is a serious complication during gestational period which affect both mother and child. Gestational Diabetes Mellitus is an intense field of research study. It shows that prevalence of Gestational Diabetes Mellitus increases by $45 \%$ but still knowledge regarding Gestational Diabetes Mellitus and self care management is very low. Hence the investigator felt that this study would help the antenatal woman to enhance their knowledge regardingGestational Diabetes Mellitus and self care practice ofGestational Diabetes Mellitus management which in turn would help to prevent complication during pregnancy.

Statement of the Problem: "A study to assess the knowledge regarding Gestational Diabetes Mellitus among pregnant mothers and self care practice of Gestational Diabetes Mellitus management among mothers with diabetes in pregnancy in selected hospitals of Kottayam District.

\section{Objectives of the Study:}

1. To assess the level of knowledge regarding Gestational Diabetes Mellitus among pregnant mothers

2. To assess the self care practice of Gestational Diabetes Mellitus management among mothers with diabetes in pregnancy.

3. To find correlation between knowledge and self care practice of Gestational Diabetes Mellitus management among mothers with diabetes in pregnancy.

\section{Hypothesis:}

$\mathbf{H}_{\mathbf{1}}$ : There is a significant correlation between knowledge and self care practice of Gestational Diabetes Mellitus management among mothers with diabetes in pregnancy.

\section{Methodology:}

Research Approach: Non experimental descriptive design

Research Design: Descriptive research design

Variables: Study variables are knowledge and practice

Setting: The study was conducted in Carmel Medical centre, Pala, Marian medical centre Palai.

Sample: Sample include 60 antenatal mothers and 15 mothers with gestational diabetes in selected hospitals in kottayam.

Sampling Technique: Non probability purposive sampling

Tool and Technique: Structured questionnaire is prepared with the help of review of literature, personal experience and discussion with experts. The questionnaire is categorized into 3 sections. 
Section 1: Consists of socio demographic data which include age monthly income, education, occupation, religion, previous history of Gestational Diabetes Mellitus etc.

Section 2: It consists of question regarding knowledge regardingGestational Diabetes Mellitus.

Section 3: It contains questions regarding self care practice of Gestational Diabetes Mellitus management.

Method of Data Collection: The formal permission for data collection was obtained from concerned authority. The actual study was conducted on 11/09/2019 to11/10/2019. By purposive sampling technique, the investigator identified 60 antenatal mothers and 15 mothers with gestational diabetes based upon inclusion and exclusion criteria.Prior to data collection, purpose of study was explained to the subjects to gain co operation. The written consent was obtained and the investigator requested to to read the instruction on the questionnaire and fill it. The data was collected and was then compiled for analysis.

Table 1: Knowledge regarding GDM among pregnant mothers $n=60$

\begin{tabular}{|c|c|c|c|c|}
\hline Knowledge range & Range percentage & Categories & Frequency & $\%$ \\
\hline $0-7$ & $0-50 \%$ & Below average & 20 & $33.3 \%$ \\
\hline $8-10.5$ & $51-75 \%$ & Average & 20 & $33.3 \%$ \\
\hline $10.6-14$ & $76-100 \%$ & Below average & 20 & $33.3 \%$ \\
\hline
\end{tabular}

Table 2: Self care practice of Gestational Diabetes Mellitus management among Gestational Diabetic mothers $n=15$

\begin{tabular}{|c|c|c|c|c|}
\hline Practice range & Range percentage & Categories & Frequency & $\mathbf{\%}$ \\
\hline $0-16.5$ & $0-50 \%$ & Poor & 0 & $0 \%$ \\
\hline $16.6-25.5$ & $51-75 \%$ & Satisfactory & 7 & $46.7 \%$ \\
\hline $24.6-33$ & $76-100 \%$ & Good & 8 & $53.3 \%$ \\
\hline
\end{tabular}

Table 3: Relationship between knowledge and practice $n=15$

\begin{tabular}{|l|c|c|c|c|}
\hline Variables & Mean & Standard deviation & Correlation & Value \\
\hline Knowledge & 9.60 & 2.58 & \multirow{2}{*}{0.043} & 0.880 \\
\hline Practice & 23.80 & 3.09 & & \\
\hline
\end{tabular}

Table shows the calculated correlation coificient(r) was 0.880 which indicate that there was apositive correlation between knowledge and practice.

\section{Discussion}

In the present study, $73.3 \%$ of pregnant women belong to the age group of 20-30 years and $26.7 \%$ belongs to the age group of $30-40$ years. $41.67 \%$ of mothers were Hindus, $41.67 \%$ were Christians and $16.6 \%$ were Muslims. In the present study it was found that $33.3 \%$ mothers had poor knowledge, $33.3 \%$ had average knowledge and $33.3 \%$ had good knowledge regarding gestational diabetes mellitus. The above findings can be supported by a study conducted among 30 mothers attending antenatal clinics of Mangalore to assess the level of knowledge regarding gestational diabetes mellitus and self care management. The results showed that $26.60 \%$ of women had poor knowledge and $20 \%$ had good knowledge. ${ }^{10}$

In the present study $46.7 \%$ had satisfactory practices and $53.3 \%$ had good practice. The results of this study is contradictory to the study conducted among Diabetes Patients in Dhaka City, Bangladesh in the year 2016 which showed that majority of patients reported regular routine follow up diet and exercise etc. for controlling DM. However, glycemic control was poor among $46.67 \%$ of respondents and $62.38 \%$ patients never performed self-blood sugar test due to lack of knowledge or lack of the feeling of necessity to do it. ${ }^{11}$ The present study 
shows that there is positive correlation $(\mathrm{p}=0.04)$ between knowledge and self care practice of gestational diabetes mellitus management among mothers with diabetes in pregancy.

\section{Recommendations:}

1. Similar study can be replicated with large sample in different settings.

2. A cross sectional study can be done to test the effectiveness of the instructional module

\section{Conclusion}

Pregnancy is a period of great change for the women in both physiological and psychological aspects. The women should adapt with these changes for the successful outcome of the pregnancy. From the present study the result showed that $33.3 \%$ had above average knowledge, $33.3 \%$ had average knowledge and $33.3 \%$ had below average knowledge regarding the gestational diabetes mellitus and the self care management. The present study shows that $46.7 \%$ had satisfactory practices and $53.3 \%$ had good practice. There is a positive correlation between knowledge and practice $(\mathrm{p}=0.04)$.

\section{Conflict of Interest: Nil}

\section{Source of Funding: Self}

Ethical Consideration: Ethical clearance was obtained from ethical committee, Govt. Medical College, Kottayam. Informed written consent was taken on the selection of the subjects. Full confidentiality was maintained throughout the study.

\section{References}

1. Edmonds DK. Dewharts Textbook of Obstetrics and gynecology. $7^{\text {th }}$ edition. Malden: Blackwell publishers; 2013: 110-112

2. Center for Disease Control and preventive reproductive health. Complications of pregnancy [Internet]. CDC: Organization; 2016 [cited on 2016 Jan 28]. Available from: http://www.CDC. gov/reproductivehealth/maternalinfanthealth/ pregnancycomplication
3. Edmonds DK. Dewharts Textbook of Obstetrics and gynecology. $7^{\text {th }}$ edition. Malden: Blackwell publishers; 2013. 246

4. Fernandus RK, Aurthur AT, Susan L. Resistance exercise programme, AJG[Abstract]. 2010[cited on 2010 Sept 14];12930:15-20. Available from: https:// www.ajg/resestanceexercise/gestationaldiabetes/

5. International Diabetes Federation. Prevalence of GDM[Internet]. IDF:Diabetes atlas.2017[cited on 2017 Aug 6]. Available from: https://www.idj.org/ our-activities/care-prenevtion/gdm

6. Rollin G. Anew definition of GDM[Internet] IJCRAR.2010[Cited on 2010 April 2];360(9):1420. Available from https://www.ijcrar.com/vol360-9

7. Tanir HM, Fener T, Enurerit, Haya M. A ten year GDM cohort at a university clinic [Internet]. IJMR.2013[Cited on 2013 March 5];32(6):241244.Available from https://www.ncbi.nlm.nih.gov/ pmc/articles/PMC3724253

8. Jeff J. GDM by 2030[Internet]IJMSPH.2018[Cited on 2018 Feb 26];3(2):191-194. Available from https://www.doi.105455/ijmph.2018.21112018/

9. Skian E, Reece EA. The impact of self monitoring glucose self efficacy and pregnancy outcome, the diabetes education.JOGI.2014.28(3)433-444

10. Daffany SN, Chakravanean S. Manual of obstetrics, updated edition of classic Holand and Brew's manual. $2^{\text {nd }}$ edition. New Delhi:Elsevier publication;2008.138

11. Joseph L, Lakshmi A.Effect of exercise on women with GDM.KMJ[Abstract].2012[cited on 2012 May 29];30(3):1225-1231. Available from https:// keralamedicaljournal.com

12. Tanija CN, Fannana T, Naved MA, Sultana S. Assessing the Knowledge, Attitude and Practice of Diabetes Mellitus. IJPCBS [Abstract]. 2016 [Cited on 2016 April 11]; 26(17):989-1003. Available from https://www.jpcbs.info/20164108Tanjia.pdf 